\title{
Large Cysticercus in the Cerebellopontine Angle: Case Report
}

\author{
Sushil Kumar Amit Garg $^{2}$ Amit Handa \\ ${ }^{1}$ Department of Neurosurgery, St Stephen's Hospital, Delhi, India \\ 2Department of Radiology, St Stephen's Hospital, Delhi, India
}

\begin{abstract}
Address for correspondence Sushil Kumar, MCh, Department of Neurosurgery, St Stephen's Hospital, Delhi, India (e-mail: sushilneuro@rediffmail.com).
\end{abstract}
Abstract
Keywords
- cysticercus
- cerebellopontine angle
$-M R I$

Neurocysticercosis is an infection of the central nervous system caused by larvae of the pork tapeworm Taenia solium. We report a case of large cyst in the cerebellopontine angle that increased in size under observation and surgery revealed it to be cysticercus. It was removed in toto and patient improved on follow-up.

\section{Introduction}

Intracranial cysticercosis is the most common parasitic infection ${ }^{1}$. Human cysticercosis is caused by ingestion of food contaminated with the ova of Taenia solium. Gastric juices dissolve the outer shell of the ova to release the primary larvae or oncospheres which penetrate the mucosa and enter the bloodstream. They can lodge in any tissue but have predilection for brain. These cysts may lodge in the subarachnoid space and become multilocular resembling a cluster of grapes. This is known as racemose form and may attain larger size. ${ }^{2}$ It predominantly involves cerebral parenchyma and ventricles. ${ }^{1,2}$ Its location in the cerebellopontine angle is rare in India, ${ }^{3}$ and because of its large size and mistaken diagnosis of tubercular arachnoiditis, it is being reported.

\section{Case Report}

A 58-year-old woman presented with headache mild to moderate in intensity radiating from forehead to neck region with slight difficulty in walking and frequent falls. There was no history of blurring of vision, incontinence, or memory impairment. On examination, the patient was conscious and fundus revealed papilledema. There was left facial upper motor neuron paresis, deep tendon jerks were brisk, and bilateral cerebellar signs were present. Magnetic resonance imaging (MRI) was suggestive of communicating hydrocephalus. Ventricular cerebrospinal fluid (CSF) was clear, colorless with glucose $50 \mathrm{mg} / \mathrm{dL}$, protein $42.2 \mathrm{mg} / \mathrm{dL}$, and no cells. CSF was negative for acid fast bacilli (AFB) on
Ziehl-Neelsen staining. Ventriculoperitoneal shunt was placed and her gait improved.

Three months later, she was readmitted in neurology service with history of low-grade fever of 1 -week duration and headache of 2 days duration. There was no sensory or motor deficit. Deep tendon reflexes (DTR) were brisk. MRI scan revealed cerebellopontine angle cystic lesion with peripheral enhancement and basal meningeal enhancement (see - Fig. 1a, b). ESR was $49 \mathrm{~mm}$ first hour Westergren. Lumbar puncture revealed protein $203 \mathrm{mg} / \mathrm{dL}$, glucose $56 \mathrm{mg} / \mathrm{dL}$, and 150 cells/cu mm, 98\% being lymphocytes. In view of earlier incompletely treated tubercular lymph adenitis of retroauricular region, the patient was diagnosed with tubercular arachnoiditis, and antitubercular (rifampicin, isoniazid, pyrazinamide, and ethambutol) drugs were started.

The patient was readmitted 3 months later with complaints of generalized weakness and imbalance on walking. On examination, patient was conscious power was grade $V$ in all limbs, mild cerebellar signs were present on the left side, and nystagmus was present with fast component to left side. Deep tendon jerks were brisk and plantar were up going bilaterally. MRI revealed enlargement of the cerebellopontine angle cystic lesion with peripheral enhancement (see - Fig. 1c, d).

Retromastoid suboccipital craniectomy revealed thickened opaque arachnoid in the cerebellopontine angle. Dissection of the arachnoid between fifth and seventh nerve revealed thin-walled cyst protruding through the dissected arachnoid. It could be delivered easily and it ruptured received

March 10, 2016

accepted

September 17, 2016

published online

April 18, 2017
DOI https://doi.org/

10.1055/s-0036-1596040.

ISSN 2277-954X.
(C2018 Neurological Surgeons'

Society of India
License terms

()(1) $\Theta \circledast$ 


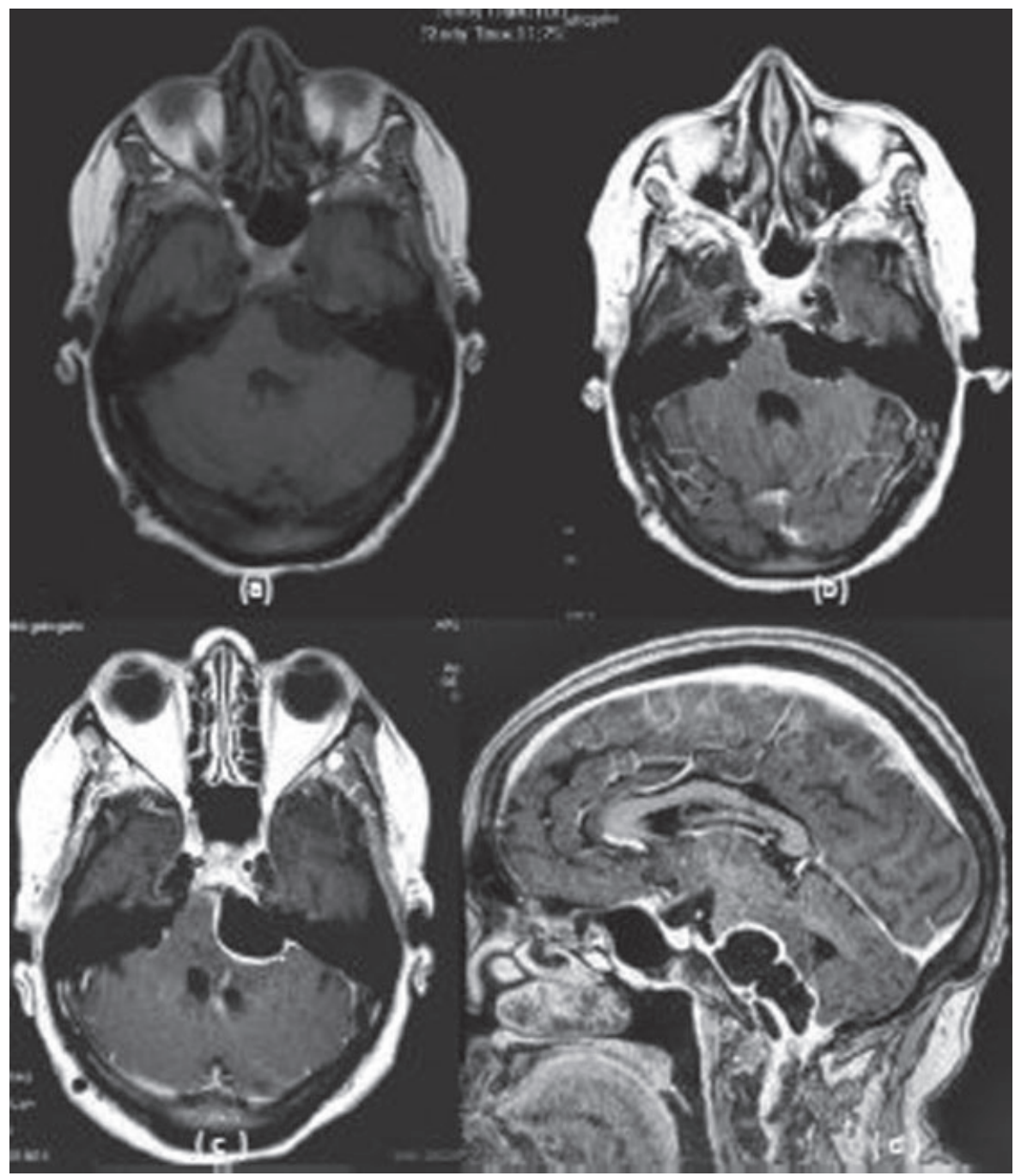

Fig. 1 Axial T1W1 image hypointense lesion in left CP angle (a) contrast T1W1 image showing peripheral and meningeal enhancement, (b) 3 months later T1W1 image showing increase size of cyst, and (c) multilocular appearance on sagittal contrast FSPGR (d).

at the last moment of delivery discharging clear fluid. - Fig. 2 shows the operative specimen.

Histopathology examination of the cyst confirmed it to be cysticercus, composed of multilocular cyst, the wall of which was folded and convoluted, without a scolex. Postoperative serology (IgM) for Taenia solium was positive, and interferon gamma in plasma was negative for tuberculosis. The patient

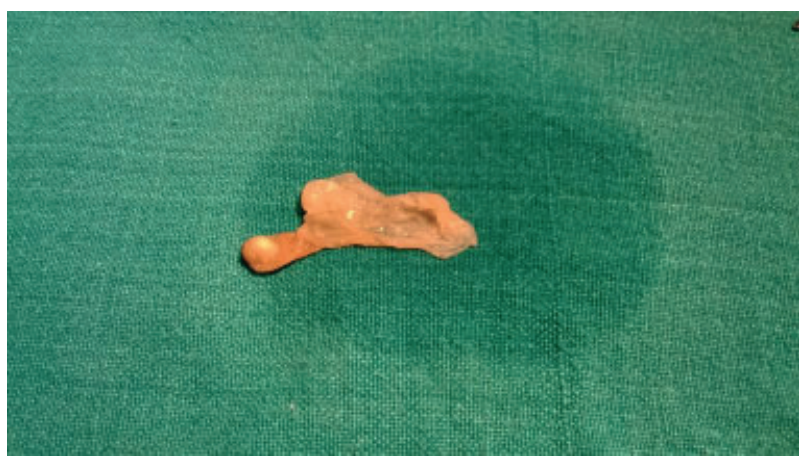

Fig. 2 Operative specimen of large collapsed cysticercus. was given a course of albendazole $400 \mathrm{mg}$ twice daily for 10 days. The patient has shown improvement during last 16 months. Her headache and ataxia have resolved and she carries out activities of daily life without any difficulty.

\section{Discussion}

Intracranial cysticercosis remains a common infective lesion and has nonspecific clinical manifestation in developing countries. Only few cases of solitary intracranial cysticercosis involving the cerebellopontine angle have been reported. ${ }^{4-7}$ Usually, the cysticerci are small lesions and cysts with largest dimension of more than 4 to $5 \mathrm{~cm}^{8}$ are called giant cysticerci. Usually, clinical manifestation results from inflammatory response to cyst degeneration, mass effect, obstruction of CSF pathway, or residual scaring ${ }^{9,10}$ but is related to the numbers, size, location of the lesion, and severity of the host immune system. Contralateral trigeminal neuralgia has been reported by Revuelta et al (1995) in ipsilateral cerebellopontine angle cysticercosis. Mural nodule on MRI is pathognomonic of cysticercus. 
In the patient, a large cystic mass was seen in cerebellopontine angle indenting the brain stem and was misdiagnosed as a cystic form of tubercular arachnoiditis in view of the past history of tubercular lesion from retroauricular region having been diagnosed as tubercular though exact nature of pathology could not be verified in view of long time elapsed since the surgery which was done at another hospital.

Multiple cyst, lobulated masses, and cystic masses have been reported in the racemose type. ${ }^{6}$ On MRI, these cysts have same signal intensity as that of CSF on all pulse sequences with no enhancement postgadolinium. Ring enhancement, however, has been reported ${ }^{4}$ and was seen by us as well. The absence of scolex and location in the subarachnoid space are in favor of this being racemose type. The differential diagnosis of such lesion includes epidermal cyst, arachnoid cyst, cystic schwannoma, cystic meningioma, and tubercular arachnoiditis. Typically, epidermoid shows irregular margins and insinuates around nerve and blood vessels; it is hypointense on T1WI, hyperintense on T2WI, and shows restriction on diffusion-weighted images. Totally cystic nonenhancing schwannoma may be difficult to differentiate on MRI, but widened auditory canal will clinch the diagnosis. Cystic meningioma can be differentiated by broadbased attachment to petrous dura, and dural tail if present can be helpful in diagnosis. Arachnoid cysts do not enhance on contrast administration and show no restriction on diffusion-weighted images.

Enlargement of the cyst was the reason for subjecting the patient to surgery. Surgery has an important role in the successful management of the intracranial cysticercosis involving the cerebellopontine angle. Cysticercosis should be removed gently to avoid its rupture.

Racemose varieties arise from the segmentation of cysticercus cellulosae with degeneration of the scolex and are nonviable. They attain large size because in the cisternal or subarachnoid space there is no limiting parenchymal tissue that can act as host response for encapsulation. Degenerative stage lacks in the racemose type. ${ }^{11}$
Even though second CSF and radiology were suggestive of tuberculosis, enlargement of the cystic lesion necessitated surgery which proved the diagnosis and was therapeutic as well. To conclude, cysticercosis be considered in the differential diagnosis of cystic lesion in the cerebellopontine angle. If the cyst enlarges on follow-up, surgery should be done for diagnosis and for treatment.

\section{References}

1 Matushita H, Pinto FC, Cardeal DD, Teixeira MJ. Hydrocephalus in neurocysticercosis. Childs Nerv Syst 2011;27(10):1709-1721

2 Couldwell WT, Zee CS, Apuzzo MLJ. Definition of the role of contemporary surgical management in cisternal and parenchymatous cysticercosis cerebri. Neurosurgery 1991;28(2): 231-237

3 Ghosh D, Dubey TN, Prabhakar S. Brain parenchymal, subarachnoid racemose, and intraventricular cysticercosis in an Indian man. Postgrad Med J 1999;75(881):164-166

4 Celis MA, Mourier KL, Polivka M, et al. [Cisternal cysticercosis of the cerebellopontine angle. A surgically-treated case and review of the literature]. Neurochirurgie 1992;38(2):108-112

5 Revuelta R, Juambelz P, Balderrama J, Teixeira F. Contralateral trigeminal neuralgia: a new clinical manifestation of neurocysticercosis: case report. Neurosurgery 1995;37(1): 138-139, discussion 139-140

6 Singh S, Gibikote SV, Bannur U, Chacko G, Korah IP, Rajshekhar $\mathrm{V}$. Cysticercosis of the cerebellopontine angle cistern mimicking epidermoid inclusioncyst. Acta NeurolScand 1999;99(4):260-263

7 Revuelta R, Soto-Hernández JL, Vales LO, González RH. Cerebellopontine angle cysticercus and concurrent vascular compression in a case of trigeminal neuralgia. Clin Neurol Neurosurg 2003;106(1):19-22

8 Hauptman JS, Hinrichs C, Mele C, Lee HJ. Radiologic manifestations of intraventricular and subarachnoid racemose neurocysticercosis. Emerg Radiol 2005;11(3):153-157

9 Del Brutto OH, Sotelo J. Neurocysticercosis: an update. Rev Infect Dis 1988;10(6):1075-1087

10 García HH, Gonzalez AE, Evans CA, Gilman RH; Cysticercosis Working Group in Peru. Taenia solium cysticercosis. Lancet 2003;362(9383): 547-556

11 Colli BO, Martelli N, Assirati JA Jr, Machado HR, de Vergueiro Forjaz S. Surgical treatment of cysticercosis of the central nervous system. Neurosurg Q 1995;5(1):34-35 